\title{
Altporn, corpos, categorias e cliques: notas etnográficas sobre pornografia online*
}

Carolina Parreiras**

\section{Resumo}

Neste artigo discuto o tema dos vídeos pornôs encontrados na internet, para pensar sobre os possíveis impactos e modificações proporcionados por essa tecnologia nos modos de representação pornográfica. A escolha do on-line se deu a partir da constatação do enorme crescimento e segmentação do mercado pornô nesse espaço, bem como das constantes tentativas nacionais $e$ transnacionais de controle do conteúdo veiculado na rede, cujos principais pontos de discussão são a pornografia, a pedofilia e a pirataria. Assim, pretendo neste paper, a partir de uma perspectiva antropológica, abordar as maneiras como o online atua no mercado erótico, especialmente no Brasil, aumentando a segmentação do gênero pornográfico e permitindo o crescimento da chamada pornografia alternativa (altporn). Para tal, tomarei como base dados de minha pesquisa empírica enfocando o site brasileiro pioneiro na produção e comercialização de pornografia alternativa. Meu intento é perceber de que modo se organiza a produção desse ramo da pornografia - com estreita ligação com os avanços tecnológicos - e quais convenções de gênero estão operando nesse segmento a partir da observação dos corpos, desejos e práticas sexuais encontrados nos vídeos e imagens.

Palavras-chave: Pornografia; Altporn; Cibercultura; Internet.

\footnotetext{
Recebido para publicação em 05 de outubro de 2012, aceito em 10 de novembro de 2012.

** Doutoranda em Ciências Sociais pela Universidade Estadual de Campinas (Área de Gênero e Sexualidade) com orientação da professora doutora Maria Filomena Gregori e financiamento da Fundação de Amparo à Pesquisa do Estado de São Paulo (FAPESP). carolparreiras@gmail.com
}

cadernos pagu (38), janeiro-junho de 2012:197-222. 
Altporn, corpos, categorias e cliques

Altporn, bodies, categories, and clicks:

ethnographic notes about online pornography

\begin{abstract}
This article discusses the topic of porn videos found on the Internet in order to think about the possible impacts and modifications provided by this technology in pornographic representation. The choice for the online was due to the tremendous growth and market segmentation of porn in this space, as well as national and transnational constant attempts to control the content posted on the network, whose main points of discussion are pornography, pedophilia and piracy. So, in this paper, I intend, from an anthropological perspective, to address the ways in which online acts in the porn market, especially in Brazil, increasing segmentation of the genre pornographic and enabling the growth of pornography so called alternative (altporn). To do this, I take examples of my database of empirical research focusing on the pioneer Brazilian website in the production of alternative pornography. My intent is to understand the ways in which this kind of production are organized - with close liaison with technological advances - and what are the genre conventions that operate in this segment from the observation of bodies, desires and sexual practices found in videos and pictures.
\end{abstract}

Key Words: Pornography, Altporn, Cyber culture, Internet. 


\section{Introdução}

Desde os primórdios da internet, ainda nos anos iniciais da década de 90, a web tem sido utilizada como meio de estabelecer relações, criar comunidades e veicular os mais diversos tipos de conteúdos, entre os quais sempre mereceram destaque representações que envolvem sexo, pornografia e erotismo. Meu foco de pesquisa atual tem sido as representações consideradas pornográficas - imagens e vídeos - disponíveis em sites gratuitos e pagos.

Nos últimos anos, a relação entre pornografia $e$ internet ficou cada vez mais destacada no debate internacional, especialmente pelo aumento da preocupação em torno da pornografia infantil, assim como da pirataria. Nesse sentido, uma série de países - o Brasil entre eles - tem feito esforços para criar legislações que incluam as práticas realizadas online. Se aprovadas, essas leis afetarão as maneiras como a internet é utilizada, criando um domínio de condutas permitidas e legítimas. Tudo que estiver fora desse domínio poderá ser enquadrado como violação à norma $e$, portanto, criminalizado e punido.

A situação atual, de certo modo, não representa uma novidade. Se formos realizar um traçado da história do que se tipifica enquanto pornografia, veremos que em muitos momentos aparecerão a clandestinidade, a ilegalidade, perseguições $e$ prisões. Diversos são os contenciosos em torno desse tema, desde as discussões jurídicas, passando pelo movimento feminista $e$ pelos interesses do mercado. Não há e talvez esteja longe de existir um consenso em torno dessa categoria e de que materiais deveriam ou poderiam ser por ela tipificados.

Se de um lado existem sucessivas tentativas de controle, do outro pode ser encontrado um crescimento cada vez maior da segmentação do mercado pornográfico, sendo que a internet atua como fator fundamental nesse processo, na medida em que permite a criação de subgêneros e nichos mais e mais específicos. 
Altporn, corpos, categorias e cliques

Só para dar uma amostra do peso da pornografia na internet: de acordo com algumas pesquisas quantitativas, cerca de $40 \%$ das atividades realizadas online envolvem algum conteúdo pornográfico. Uma das pesquisas nesste sentido, conduzida pela HitWise (empresa de consultoria e marketing on-line) em 2008, calcula que cerca de $10 \%$ das buscas feitas pelos internautas envolvem pornografia (sex e porn aparecem como algumas das palavras mais procuradas no Google). Outras pesquisas ${ }^{1}$ feitas em 2009 afirmam que, em média, 43\% dos usuários da internet ao redor do mundo acessam material considerado pornográfico e que $35 \%$ de todos os downloads realizados envolvem pornografia. Tancer (2009), a partir da base de dados da Hitwise, se propôs a entender o que as pessoas fazem quando estão online. $\mathrm{O}$ que os dados mostraram é que parte considerável dos acessos ${ }^{2}$ envolvia

1 Estas pesquisas são realizadas anualmente com os mais diversos fins. Em geral, os responsáveis pelos levantamentos são empresas de consultoria, órgãos governamentais, organizações anti-pornografia (a principal delas é a National Coalition for the Protection of Children \& Family, sediada nos Estados Unidos), jornais e revistas ou mesmo as empresas envolvidas na produção e distribuição de conteúdo pornográfico. Sem dúvida, os dados primam pela inexatidão e muitas vezes pela falta de neutralidade, o que faz com que devam ser olhados com cuidado. Isto se deve aos interesses envolvidos na execução dos levantamentos e na já apontada dificuldade de mapear a web. Para maiores informações ver www.nationacoalition.org; http://www.cnbc.com/id/29960781/; http://www.pbs.org/wgbh/pages/frontline/shows/porn/business/.

2 Mais algumas estatísticas podem ajudar a entender um pouco melhor a relevância de materiais pornográficos na web. Uma das mais replicadas (inclusive pelo governo norte-americano) é a de Philip Stark (2008), na qual ele afirmava a partir de dados fornecidos pelo Google e pela Microsoft - que a Internet é $99 \%$ porn-free. Tancer (2009), apesar de possuir uma base de dados limitada (a Hitwise só possuía levantamentos de acesso dos Estados Unidos, Reino Unido, Hong Kong, Cingapura, Austrália e Nova Zelândia), fornece informações diferentes e mais detalhadas, apesar de fazer a ressalva da dificuldade de mensurar tanto o tamanho da indústria pornográfica quanto dos que a acessam. De acordo com ele, em 2007, sua base de dados contava com 40.634 sites de conteúdo adulto, sendo que isto representava $10 \%$ de todos os sites disponíveis ali. Neles, cerca de $72,6 \%$ dos acessos eram feitos por homens. Alguns outros cruzamentos de dados são interessantes, como por exemplo, a quantidades de 
pornografia. Outro insight valioso no levantamento de Tancer diz respeito aos modos como as mudanças na web foram importantes para a produção e consumo de pornografia online. De acordo com ele,

Se pensarmos no verão de 2007, o mesmo termo de busca ("sexo") direcionou tráfego para sites de vídeo online (www.metaface.com e video.google.com), para uma enciclopédia social (www.wikipedia.org) e para a rede social MySpace, indicando que o consumo de conteúdo adulto havia se movido do mundo estático de exibição de vídeos e imagens para o mundo da web 2.0, onde mídia gerada e consumida pelos usuários $e$ as redes sociais possuem um papel central ${ }^{3}$ (Tancer, 2009:35).

acesso à pornografia nos dias da semana ou mesmo a porcentagem de republicanos ou democratas que a consomem.

3 If we fast-forward to the summer of 2007, that same search term ("sex") drove traffic to online video sites (www.metaface.com and video.google.com), a social encyclopedia (www.wikipedia.org) and social network MySpace, indicating that consumption of online adult content has moved from the world of static display of images and video to the world of Web 2.0, where consumer-generated media and social networks now play a key role. [tradução minha]. 
Altporn, corpos, categorias e cliques

Com a chamada web $2.0^{4}$, houve um aumento de possibilidades de produção, comercialização e interação. Não se trata apenas de avanços tecnológicos, com a melhoria da qualidade de imagens e sons, mas, sobretudo, de novas alternativas de criação. Como não é mais necessária uma expertise para utilizar os programas e a tecnologia se tornou cada vez mais móvel, qualquer pessoa é um produtor em potencial. Vem daí o significativo crescimento na quantidade de vídeos amadores, o aparecimento de uma série de sites com interação via webcam e, como um efeito interessante desse processo, o fortalecimento de gêneros alternativos ao mainstream, como, por exemplo, o altporn, o kink (pornografia BDSM e fetichista) e a pornografia feminista.

Então, minha proposta é pensar como se deu, no caso brasileiro, o surgimento de ramos de pornografia alternativos ao mainstream e que se utilizam grandemente do virtual como forma de divulgação e até mesmo para a formação de comunidades de consumidores/produtores. Isso se mostra relevante na medida em

4 O termo Web 2.0 foi criado nos anos 2000 por uma empresa norte-americana chamada O'Reilly Media e veio para nomear uma segunda geração de comunidades e programas da Internet. De maneira geral, o termo web 1.0 designa as chamadas ponto.com, sendo que há um grupo de pessoas que produzem sites, programas, aplicativos e uma grande massa de consumidores. A inflexão contida no conceito de web 2.0 é a possibilidade de expandir a ideia de produção, sendo que cada usuário passa a ser um potencial produtor $e$ consumidor. A Web passa a ser vista como plataforma e permite o surgimento das wikis (exemplo é a wikipedia), o desenvolvimento de redes sociais diversas e a "folksonomia" (ou processo de usar marcadores - tags - como forma de indexar informações). Entre os princípios centrais da Web 2.0 estão a colaboração; a confusão de fronteiras entre produção e consumo; a possibilidade de ampliar os conceitos de comunidades e interação online para englobar variadas ferramentas geradoras de redes sociais e também as chamadas mídias sociais; revisão da questão dos direitos autorais, com o surgimento de alternativas como as licenças Creative Commons; utilização de plataformas abertas (API). Outra ideia da web 2.0 que passa a ser bastante utilizada pelas pessoas ligadas à pornografia são as mídias e redes sociais. Foi também através delas que iniciei a pesquisa de campo, sendo que os primeiros contatos com as pessoas que produzem altporn no Brasil se deram por meio de uma ferramenta de mídia social. 
que fornece elementos para pensar nos modos como as sexualidades são representadas e vivenciadas nesses novos segmentos do pornô, seja enquanto rompimento com padrões da pornografia mainstream ou como geradores de novas convenções e categorias.

As discussões apresentadas neste artigo, assim como os dados etnográficos que as sustentam são fruto de minha pesquisa de campo cujo foco tem sido a única produtora de altporn no Brasil: a XXP. ${ }^{5}$ Venho acompanhando todo o processo de produção até que os vídeos estejam editados e sejam alocados no site, bem como as variadas interações que envolvem pessoas, avatares, tecnologia, mídias/redes sociais (Facebook e Twitter), sexo, pornografia, a própria pesquisadora e o mercado erótico em um sentido mais amplo. Em última instância, a compreensão dessas muitas relações e de como esse cenário se organiza me permite pensar não apenas o encontro entre pornografia $e$ internet, mas também a própria relação entre aquilo que chamamos de online e offline. ${ }^{6}$

O texto está organizado em dois eixos. No primeiro, faço uma revisão teórico-metodológica acerca dos estudos sobre pornografia e erotismo e especialmente a respeito dos que tratam de sua relação com a internet. Na parte final, enfoco a XXP, a produção dos vídeos e as relações que venho acompanhando em uma tentativa de fornecer os primeiros passos para $\mathrm{o}$ entendimento do que se nomeia pornografia alternativa, com que

\footnotetext{
5 Saliento que o nome dos sites, da produtora e dos meus colaboradores de pesquisa foram modificados a fim de evitar sua exposição.

6 Como afirmei em minha dissertação de mestrado (Parreiras, 2008), parto de uma perspectiva teórica e metodológica que tenta fugir das recorrentes polarizações estabelecidas entre on e offline. Como apontam Miller e Slater (2004), uma boa saída é pensar em contextos a fim de evitar recair em conceitos pré-formados como virtualidade, ciberespaço e também pensar online e offline como auto-contidos ou dotados de unidade. Assim procedendo, passa a ser possível ir além da divisão entre online e offline e pensar que esses polos, quando existem, são definidos de forma contingente.
} 
Altporn, corpos, categorias e cliques

convenções de gênero e sexualidade ela opera e quais relações sociais mobiliza.

\section{Pornografia, internet e estudos acadêmicos: um breve histórico}

Discussões que envolvem os temas pornografia e erotismo estão quase sempre cercadas por uma série de contenciosos. Já de início não há um consenso entre o que se tipifica como cada um deles, sendo que os dois termos aparecem imersos em disputas jurídicas, do mercado, do movimento feminista e acadêmicas. Vale salientar que trabalho com uma perspectiva que pensa pornografia e erotismo como construídos contextualmente a partir de diferentes posições de poder. Desse modo, eles não possuem um significado intrínseco e estão em um constante processo de transformação.

Apesar da existência de um campo consolidado de estudos que enfocam representações pornográficas, é possível notar nos últimos anos uma diversificação dos temas, entre eles o entendimento das relações entre tecnologia e pornografia.

De acordo com Feona Attwood (2002), ao realizar uma avaliação do campo de estudos sobre erotismo e pornografia pode ser percebida uma mudança de paradigma em sua teorização. Ela localiza em duas obras a posição de referências centrais para essa mudança: The Secret Museum (Kendrick, 1995) - que pensa historicamente a pornografia como categoria - e Hardcore (Williams, 1999) - em que há uma análise dos textos pornográficos enquanto textos. A inflexão principal e que permite pensar na modificação de paradigmas é que a pornografia deixa de ser pensada a partir apenas de posições radicais ou em termos dos males ou consequências que causa aos que a consomem e passa a ser estudada a partir de um viés contextual. Em paralelo a essa mudança de enfoque, Attwood aponta a crescente influência dos cultural studies, o desenvolvimento de novas vertentes do movimento feminista que engrossam as posturas pró-sexo, e também modificações nas representações midiáticas de sexo e sexualidade. 
No Brasil, há alguns anos vem se estabelecendo um campo de estudos sobre mercado erótico, sendo a pornografia um de seus eixos. Destacam-se como referências importantes investigações sobre: pornografia bizarra (Leite Jr, 2006); as novas faces do erotismo (Gregori, 2010); relações eróticas entre homens em clubes de sexo (Braz, 2010); mulheres e práticas BDSM (Facchini, 2009) e sobre os bastidores da indústria pornográfica mainstream nacional (Díaz-Benítez, 2010).

O momento atual seria assim marcado por uma variedade de pornografias, as quais, em alguns casos, tentam unir o sexualmente explícito e a política radical, como por exemplo, a chamada pornografia feminista. Na medida em que proliferam diversas segmentações do gênero pornográfico e surgem novos nichos o que se tem é a dificuldade crescente de estabelecer fronteiras entre pornografia $e$ outras formas de representação.

Nesse processo de segmentação, o online entra como um dos principais fatores a partir do momento em que modifica os modos como as pessoas produzem e consomem pornografia. Um breve comentário de caráter metodológico se mostra necessário, até mesmo para situar de onde partem os dados que serão apresentados no decorrer deste texto. Em minhas pesquisas sempre tento trabalhar e realizar a incursão empírica a partir de uma alternativa fornecida e facilitada pela internet: seguir fluxos (de dados, informações, pessoas, convenções). Como ficará claro, apesar de partir da internet, esta pesquisa não fica restrita a ela. Ao acompanhar os deslocamentos e fluxos que envolvem as pessoas ligadas ao mercado erótico, ao próprio aparato tecnológico e à pornografia, notei que muitos outros lugares, relações e espaços são mobilizados para que se dê a produção de altporn.

Ao pensar especificamente nesse encontro entre pornografia $e$ internet, destacam-se - desde quando ainda se falava em web 1.0 -, algumas pesquisas em diferentes áreas das ciências sociais que ensinam um pouco sobre o peso dessa atividade no online. Slater (1998) reflete sobre a troca se "sexpics" - entendidas como qualquer material sexualmente explícito - no IRC (Internet Relay 
Altporn, corpos, categorias e cliques

Chat), um dos primeiros mecanismos da web a permitir o compartilhamento de arquivos entre os usuários.

De acordo com Williams (2008), a crescente preocupação de governos e empresas com a pornografia se justifica pela entrada maciça das representações eróticas nas casas, com o diferencial de que o online ainda permite interação em tempo real e a própria colocação do internauta - por meio de seu avatar e da virtualização de seu corpo - no meio da cadeia de relações. Não se trata mais apenas de um espectador passivo que olha para a tela, mas de um corpo/avatar que interage e que se transforma em alguém que produz (o exemplo que ela mais explora são os sites de interação por webcam). Além disso, a autora salienta que as experiências de cyberporn podem ser múltiplas e estão disponíveis aos internautas a partir de diferentes canais, abarcando desde os filmes mainstream mais convencionais até iniciativas que rompem com certas convenções. Assim,

As experiências de cyberporn de hoje podem abranger alugar ou comprar um DVD, fazer o download de um jogo, logar em um site como cam.whore, comprar um one-shotonly pay for play, visitar variados websites que oferecem diversos shows sexuais e orientações, ou interagir através de sexo virtual através dos corpos de seus avatares em jogos "massively multi-player" como o Second Life ${ }^{7}$.

(Williams, 2008:321)

Ainda entre as produções que tomam como foco a pornografia na internet, Attwood (2007) é uma das principais referências quando se fala em estudos sobre pornografia alternativa. Ela se propõe a pensar em sites que entrariam

7 Experiences of cyberporn today might entail the renting or purchasing of a DVD, downloading a game online, logging onto a cam.whore site, engaging in one-shot-only pay for play, visiting any number of Web sites offering any number of sexual shows or orientations, or integrating virtual sex through the bodies of avatars into the daily life of 'massively multi-player online' games such as Second Life. [tradução minha] 
nessa classificação, sendo um deles o SuicideGirls ${ }^{8}$ (www.suicidegirls.com), que acabou se tornando o exemplar mais conhecido e bem-sucedido de altporn. Esses sites representariam uma alternativa ao pornô mainstream e combinariam os eixos comércio e comunidade: são sites pagos, mas que possuem a intenção de unir pessoas que apreciem a estética pornográfica que veiculam em um grupo que interage online. A autora acredita que o online não é simplesmente uma extensão da pornografia comercial offline, mas cria novas oportunidades de produção $e$ consumo, nublando, em muitos momentos, a divisão entre produtores e consumidores (exemplo são os vídeos amadores ou mesmo os sites de webcam ao vivo). Além disso, haveria uma modificação na lógica da indústria $e$ alterações em algumas das convenções encontradas nos filmes pornôs. Desse modo,

\begin{abstract}
o rápido crescimento de novas formas de pornografia online e de gostos culturais que crescem em torno delas estão nublando as fronteiras entre o pornô $e$ outras estéticas, entre formas de sexo comercial e não-comercial, entre consumo $e$ comunidade $e$ entre sexo como representação e auto-apresentação, recreação e relação. Isto coloca novas questões sobre o que queremos dizer com sexo comercial e como podemos realizar seu estudo 9 (Attwood, 2007:453).
\end{abstract}

8 O Suicide Girls foi criado em 2001 com o propósito de ser uma comunidade "para celebrar a beleza alternativa" e fora dos padrões referendados por exemplo na moda. O site conta com um grande acervo de fotos de mulheres que seguem uma mesma estética: tatuadas, com piercings, cabelos pintados, indumentárias e poses de pin-ups, góticas ou indie.

9 The rapid growth of new forms of online pornography and the taste cultures that grow up around them are blurring the boundaries between porn and other aesthetics, between commercial and non-commercial forms of sex, between consumption and community, and between sex as representation and selfpresentation, recreation and relation. It poses new questions about what we mean by commercial sex and how we might develop its study. [tradução minha] 
Por fim e antes de entrar em minhas notas etnográficas, acredito que faça sentido pensar em uma diferenciação dos materiais pornográficos encontrados online. Paasonen (2010) chama a atenção para a existência de duas possibilidades estéticas, políticas, econômicas e tecnológicas: o porn on the net e o netporn. O porn on the net seria uma reciclagem de vídeos, textos $e$ imagens pornográficos e sua alocação em sites. Não são materiais pornográficos produzidos especificamente para a internet e podem ser facilmente encontrados em sites de acesso gratuito similares ao YouTube. Associado comumente com o que se chama de indústria pornográfica, esse material é marcado pela estandardização, consumo passivo e lógica da mesmice (Paasonen, 2010).

Já o netporn se caracteriza por representar pornografias próprias das plataformas e redes online. Os maiores exemplos são o altporn e os vídeos amadores. Alguns pontos são marcantes quando se fala em pornografia produzida especificamente para a internet $e$ com as possibilidades fornecidas pelas novas tecnologias: revisão das fronteiras entre produtores $e$ consumidores, crescimento na quantidade de manifestações alternativas ou independentes, tentativa de modificação nas convenções do pornô mais convencional, referencial queer e nãonormativo, busca de ruptura com práticas consideradas opressoras e encontradas no mainstream (exemplo é a pornografia feminista), resistência à comoditização (commoditization).

Ainda que se estabeleçam essas duas tipificações, cabe salientar que as fronteiras entre elas são tênues e estão sendo negociadas em diferentes cenários. Não é possível dizer, por exemplo, que toda pornografia alternativa não visa ser comercial ou gerar lucro. $\mathrm{O}$ que ocorre é a formação de novos mercados com um público consumidor de cada um dos vários tipos de produções e das estéticas próprias de cada uma delas. Assim,

Pornografias alternativas (netporn) têm sido, desde os sites kink até as pornografias subculturais, alimentadas pelas imagens da pornografia comercial (porn on the net) 
que aparentemente subvertem. Se as pornografias independentes se apropriam de elementos do chamado pornô mainstream enquanto abandona ou ignora outras, este é um caso em que há vice-versa ${ }^{10}$ (Paasonen, 2010:1301).

\section{Altporn no Brasil: a XXP}

Falar em pornografia na internet é imediatamente invocar uma série interminável de representações que vão desde os sites gratuitos $^{11}$ e agregadores dos mais diversos segmentos de vídeos pornográficos (Xvideos, RedTube, YouPorn e PornoTube), até sites pagos e dedicados a nichos de mercado cada vez mais específicos.

Ao seguir os muitos fluxos propiciados pelos mapeamentos que realizei online, acabei por centrar o foco em representações que fossem possíveis a partir de e no online, ou seja, que estivessem em intrínseca relação com as novas tecnologias e as oportunidades por elas oferecidas. Foi desse modo que cheguei à $\mathrm{XXP}$, único empreendimento de altporn no Brasil.

A XXP teve suas origens no ano de 1998 quando três amigos que possuíam uma banda de punk rock resolveram pegar uma câmera emprestada e fazer um vídeo pornográfico com bonecas Barbie. Esse vídeo - intitulado Plastic Lesbians - acabou sendo selecionado para o Festival MixBrasil e apresentado no Museu da

\footnotetext{
${ }^{10}$ Alternative pornographies (i.e. netporn) have, from kink sites to subcultural pornographies, fed back to the imageries of commercial pornography (porn on the net) that they apparently subvert. If independent pornographies appropriate poses and elements from the so-called mainstream while abandoning or disregarding others, this is also the case vice versa. [tradução minha]

${ }^{11}$ Apesar de nenhum desses sites gratuitos estar hospedado em domínio brasileiro, são bastante utilizados por internautas do Brasil. No início da pesquisa, essa parecia ser a melhor alternativa por se tratarem de plataformas de acesso fácil e gratuito. No entanto, optei por não centrar o foco neles. Eles estão presentes como subtexto, visto que são um canal privilegiado para chegar aos vídeos amadores $e$ também me permitem entender quais são e como estão sendo empregadas no online as muitas categorias classificatórias das representações pornográficas.
} 
Altporn, corpos, categorias e cliques

Imagem e do Som de São Paulo, momento em que eles resolveram abandonar a música e investir em pornografia. Apesar de contar com três sócios, grande parte do trabalho - desde os roteiros até sua execução e posterior edição - é feita por Rufus ${ }^{12}$ e Lola. ${ }^{13}$

Como me narrou Rufus, o início era bastante amador, com a mistura entre música e gravação de vídeos. A internet entra no processo de produção logo a seguir, sendo que foi através dela que eles chegaram à primeira atriz - um nome bastante conhecido no mercado pornográfico brasileiro na década de 80 e precursora dos sites de câmera - que trabalhou com eles. O primeiro filme foi feito sem orçamento, a atriz não recebeu cachê e o enredo girava em torno de situações propiciadas pela internet: encontros online, uso de webcam para masturbação, sendo que o ápice do vídeo é quando ela se masturba com um joystick de Atari.

Nessa mesma época, eles editavam um fanzine - o JB (nome utilizado até hoje no avatar da produtora no Facebook e também para dar nome à personagem criada para assinar os textos contidos no fanzine: uma cafetina de nome JB) que circulou por cerca de 2 ou 3 anos. Os primeiros vídeos - ainda em VHS - eram distribuídos com o fanzine e enviados aos compradores pelo correio.

As entrevistas que realizei deixam claro que nessa fase inicial não havia por parte deles qualquer tentativa de enquadrar suas

\footnotetext{
${ }^{12}$ Rufus é um dos sócios da XXP. Todas as produções contam com sua participação e a maioria das ideias de roteiros é de sua autoria. É ele também que administra a parte financeira da produtora, empresta o apartamento para algumas gravações, atua como motorista para as atrizes e os outros sócios (é o único que dirige), bem como quem realiza todos os contatos de parceria. Além disso, é um geek (viciado em tecnologia) assumido e cuida de todos os perfis XXP na internet (Twitter, Facebook, Foursquare).

${ }^{13}$ Lola é a produtora da XXP. Foi a responsável por minha entrada em campo, já que após nos conhecermos em uma feira erótica em 2010, ela facilitou todos os contatos com Rufus. Na produtora, ela é uma "faz tudo": cuida de burocracias, como locação de lugares para filmagem, contratos e preparação das atrizes. Recentemente, passou a fotografar as filmagens e a atuar de forma mais direta nas gravações.
} 
produções em um segmento específico de pornografia. O rótulo altporn só aparece anos depois, como me narrou Rufus:

Nessa época ainda o tema altporn não existia pra gente. Não tinha um nome. A gente fazia pornografia. A gente gostava de Buttman ${ }^{14}$ e estávamos fazendo pornografia. $\mathrm{O}$ mais próximo que a gente tinha andado foi que a gente viu uma vez... na Galeria do Rock tinha uma revista, que a gente não comprou porque era muito cara, com punks nus. Aquilo foi a primeira coisa de altporn que eu vi na minha vida. Era uma revista europeia acho. (...) Até aí isso não existia pra gente. A gente estava fazendo pornografia $e$ ponto final.

Apesar de não possuir uma denominação, é possível reconhecer neste início alguns traços que caracterizaram as produções como altporn: o padrão de corpos exibidos - de meninas tatuadas ou com algum outro tipo de body modification e que se identificariam com uma cena mais alternativa $e$ independente (nerd, indie e associada, na cidade de São Paulo, ao chamado Baixo Augusta) em termos de músicas e estilos de vida o uso de sex toys ${ }^{15}$ e a presença de algumas cenas fetichistas e de BDSM, como podolatria, amarrações.

A produção de vídeos só se tornou um negócio nos anos 2000, sendo que durante algum tempo eles produziram materiais que eram distribuídos em DVD por empresas ligadas ao mainstream e possuíam algum conteúdo em blogs (primeiro na plataforma HPG e depois no Blig). É nesse momento que eles registram a produtora com o nome de Red Light. Hoje, ela está dividida em três sites: a XXP, dedicada ao altporn; o Fetxxx, no qual o foco são vídeos fetichistas e com práticas de BDSM (Real

${ }^{14}$ Buttman é uma produtora de pornografia mainstream, fundada por John Stagliano e que se tornou famosa pelos filmes gonzo (uma mesma pessoa dirige, atua e opera as câmeras e não há cortes ou edições).

${ }^{15}$ Para mais reflexões sobre o uso de sex toys, ver Gregori (2010) e Preciado (2002). 
Altporn, corpos, categorias e cliques

BDSM powerplay, submissive beautiful women, slaves, fendom, submissive males violated by beautiful dominatrices, hot piss on wet pussy, slave training, anal playground ${ }^{16}$ ) e o Fsxxx, uma espécie de amador profissionalizado (flagras, amadores, putaria, bandalheira e safadeza). Recentemente eles lançaram também um site chamado BP (Encontre a mulher que você procura), dedicado à busca de atrizes pornô. Nesse site estão perfis dessas atrizes com seus contatos e modos como podem ser encontradas: telefones, Twitter, Orkut, Facebook, site pessoal e, caso elas também atuem como garotas de programa ou acompanhantes, link para sua avaliação no GP Guia. ${ }^{17}$

Apesar dessa separação, ou desses vários "experimentos", como eles mesmos descreveram em uma postagem do Twitter, o eixo que une os três sites é a ideia de fazer algo que fuja das práticas pornográficas mais convencionais associadas ao mainstream. Mesmo que haja a criação de classificações mais específicas, como por exemplo, pornografia fetichista, ainda assim trata-se de algo comparativamente mais alternativo, independente $e$ alinhado com uma certa estética que tenta romper com os padrões de corpos, práticas sexuais e desejos presentes na pornografia mais convencional e comercial.

Na descrição do site antigo - o novo acaba de entrar no ar eles mesmos tentam definir o que fazem:

A XXP é a reunião de três caras e diversos grupos de
pessoas que juntos produzem pornografia. Nada do que
fazemos é arte. Podemos nos apropriar do trabalho de
outros artistas, mas tudo que passa por aqui se transforma
em pornografia. Ignoramos o que chamam de erotismo ou
nudez artística. O erotismo é a pornografia dos oprimidos.

\footnotetext{
${ }^{16}$ Play BDSM real, belas mulheres submissas, escravos, dominação feminina, homens submissos violados por belas dominatrizes, urina quente em bucetas molhadas, treinamento escravo, playground anal.

${ }^{17}$ GP Guia é um site onde é possível encontrar garotas de programa e suas avaliações baseadas nas notas dos usuários que já contrataram seus serviços.
} 
(...) Acreditamos em conexões, por isso contamos com outras pessoas e grupos para tornar tudo o que fazemos mais interessante: bandas, estilistas, poetas, prostitutas, webdevelopers, escritores, amigos bêbados, jornalistas, strippers, designers, dançarinas, engolidoras de fogo, fotógrafos, atrizes e atores da indústria pornográfica, camelôs, locutores, videomakers, enfim, uma revoada de desajustados.

Fica clara a ideia de unir pessoas de diversas origens $e$ posicionadas em diferentes lugares em torno da produção de pornografia. Esse foi um dos primeiros pontos que me chamou a atenção, não apenas por estar no site e ser reafirmado nas postagens do Twitter, mas também nas entrevistas. Por detrás do empreendimento, há a vontade de criar em torno do pornô alternativo uma comunidade de pessoas que partilham certas ideias e gostem de uma determinada estética, cujo objetivo inicial é fugir dos ditames - de corpos, sexualidades, desejos e prazeres da pornografia mais convencional, mas não se resume apenas a ela. Envolve um estilo de vida com músicas, jeitos de vestir, lugares $e$ pessoas que consomem esse estilo. Veio daí a ideia de reformular o site e transformá-lo em uma plataforma mais interativa. Aproveitando as possibilidades da web 2.0, a ideia é interligar pessoas que de algum modo estão envolvidas com a pornografia, sejam elas produtores, atrizes e atores, fotógrafos, bandas que queiram atrelar seu trabalho ao site e ao público consumidor.

Caminha nesse sentido a modificação da logomarca do site. Onde antes apareceria escrito "XXP. Adulterando o submundo" hoje se lê "XXP. Conectando o submundo". Apenas esses dois logos já oferecem uma série de elementos para pensar e entender melhor os modos como pornografia, pessoas $e$ internet se organizam quando se fala em altporn. O primeiro ponto é a presença da palavra submundo. À primeira vista, esse termo pode parecer depreciativo, graças ao prefixo sub-, mas penso que ele tem um sentido muito claro. Caminha lado a lado com as propostas mais amplas dos criadores da XXP, as quais estão 
Altporn, corpos, categorias e cliques

colocadas na descrição transcrita acima: nesse site as pessoas vão encontrar pornografia - e um tipo muito específico dela -, mas também uma estética que a acompanha. De certo modo, isso se assemelha ao apontado pela literatura internacional (Attwood, 2007 e Paasonen, 2010) sobre altporn, gênero que aparece quase sempre ligado a certas subculturas, tendências e estéticas independentes.

Cabe, no entanto, uma ressalva: utilizo submundo $e$ subcultura enquanto termos êmicos. A antropologia possui uma longa tradição de discussão destes conceitos e prefiro trabalhar teoricamente com as ideias de fluxos e redes, a fim de não encapsular os sujeitos como parte fixa de um grupo ou comunidade. Fluxos permitem pensar em conexões, contingências e relações que estão o tempo todo se construindo e reconstruindo.

Submundo funciona para a XXP como o agregador de pessoas, práticas, espaços, atos sexuais, corpos e estilos de vida que fugiriam daqueles tomados como mais tradicionais/ convencionais. E isso está expresso nos vídeos, fotos, locações escolhidas para as filmagens, corpos que entram em cena (tatuados, com piercings e não necessariamente ligados aos padrões de beleza socialmente mais valorizados), postagens no Twitter e nas parcerias que firmam com diferentes pessoas ${ }^{18}$ ligadas ou não ao mercado erótico - que circulam por lugares $e$ estilos mais alternativos.

Em relação à mudança do verbo que acompanha a palavra submundo, acredito que há uma inflexão importante: quando adulterando (sinônimo de corrompendo - e aqui talvez haja a ideia de que a pornografia transgride certas convenções $e$ moralidades) é substituído por conectando a mensagem que eles desejam transmitir muda e passa a fazer parte de uma iniciativa

\footnotetext{
${ }^{18} \mathrm{Se}$ formos traçar um perfil mais sociológico dessas pessoas, levando em consideração o cruzamento entre os marcadores sociais da diferença, tratam-se de pessoas brancas, na faixa etária de 20 a 40 anos, de classe média, com nível superior completo ou em vias de concluir, com trabalhos fora do mercado erótico e dotadas de um capital cultural que as permite acesso às novas tecnologias e à própria cena alternativa paulistana.
} 
em que a modificação do site é peça fundamental. Ao aproveitar as possibilidades oferecidas por plataformas digitais cada vez mais interativas, o site passa a ser mais funcional $e$ a permitir que os assinantes criem perfis para interagirem com outros membros (quem faz a XXP, atrizes, produtores, bandas, colaboradores). As parcerias são múltiplas: bandas identificadas com a cena mais independente e que queiram divulgar seu trabalho no site e/ou nos filmes, outros sites de conteúdo relativo ao sexo, festivais de filmes, projeto de resgate do burlesco. De acordo com Rufus, a ideia da XXP é ser "um hub de subcultura".

Também fica claro - e aqui o Facebook e o Twitter da produtora são estratégicos para perceber as interações e possíveis redes de relações - a tentativa de agregar o público consumidor. A meu ver, o momento em que isso acontece de forma mais clara é quando eles realizam transmissões das gravações através de uma ferramenta disponibilizada pelo Twitter - as Twitcams. ${ }^{19}$ A primeira dessas transmissões teve como conteúdo a gravação de uma cena entre Andressa - uma atriz bastante participativa no Twitter e que mais tarde passou a se intitular uma especialista em TwitCam - e Momo - atriz muito conhecida do público brasileiro e cujo perfil no Twitter passava dos 20 mil seguidores.

A TwitCam foi marcada para um sábado à tarde e a cena foi transmitida gratuitamente e em tempo real para todos os usuários que quiseram assistir. $\mathrm{O}$ link para a transmissão foi postado nos perfis de Andressa, Momo, Red Light e Lola ${ }^{20}$ (e instantaneamente replicados via retweet). No período de pico, com 2 câmeras abertas, registrei cerca de 20 mil acessos (não há como dizer 20 mil pessoas porque o mesmo indivíduo poderia acessar as 2 câmeras simultaneamente).

\footnotetext{
${ }^{19}$ Como na Twitcam cresceu a censura e a intolerância com perfis em que haja pornografia, agora eles utilizam o Twitcast. Ambos possuem um funcionamento similar e bastante simples: há uma câmera que transmite em uma página associada a uma conta do Twitter. Qualquer pessoa pode acessá-la e também postar comentários em tempo real.

${ }^{20}$ Ela cuida da parte de produção e das burocracias da XXP.
} 
Durante a TwitCam também houve a revelação de que o perfil de Momo no Twitter era fake e havia sido criado por um fã.

Acredito que a ideia de realizar a transmissão do modo como uma cena pornográfica é concebida e realizada tem muitas explicações. Além de divulgar a produtora e o material por ela produzido, a TwitCam conseguiu conferir aos atos transmitidos uma certa dose de realidade, percebida através das ordens do diretor, das dicas de posicionamento para as atrizes, dos fotógrafos se movimentando, das conversas das atrizes antes, durante $e$ depois da cena. Além disso, foi uma tentativa de aproximar o público das atrizes e das pessoas por detrás das cenas, as quais, de outro modo, só chegariam aos consumidores após a edição.

Em relação ao conteúdo do site, cabem algumas considerações. Como mencionei em outras partes deste texto, um dos principais objetivos do altporn é subverter alguns princípios presentes na pornografia mais tradicional ou mainstream. De modo geral, os filmes mais convencionais seguem uma fórmula $e$ um script: filmes heterossexuais ou lésbicos para homens; centralidade do sexo anal; apagamento do homem, que se resume ao pênis (na grande maioria dos vídeos, não aparece nem mesmo o seu rosto); obrigatoriedade do gozo, observável pelos gemidos e outros sons geralmente femininos e pelo pênis que ejacula - o chamado money shot - em direção à câmera e preferencialmente no rosto da atriz.

Esse roteiro é muito semelhante àquele descrito por DíazBenítez (2010) em sua etnografia sobre os bastidores da indústria pornográfica brasileira. De acordo com ela, o pornô apresenta um sexo coreográfico e ritualizado, com posições sexuais muito específicas e de duração padronizada. Um ponto que chama a atenção é a tentativa de mostrar sempre posições que fogem do "papai e mamãe", supostamente o tipo de sexo praticado pelas pessoas em geral. Com isso, há uma proliferação de "novas" posições e a centralidade do ânus, cuja penetração seria uma transgressão às normas. 
O altporn também opera a partir de um script e de convenções muito próprias, mas seu pano de fundo é quase sempre mostrar posições, práticas, fetiches, desejos e corpos que normalmente não aparecem no pornô mainstream. O primeiro ponto que chama a atenção é a pouca participação de homens nas cenas e fotos. A grande maioria das produções traz apenas mulheres, sozinhas ou interagindo entre si. Nas entrevistas, tanto com quem produz os vídeos, quanto com as atrizes, o mesmo fator é mencionado para explicar a ausência de homens e de material com temática gay: a dificuldade de encontrar entre os atores brasileiros corpos que se enquadrem no que a XXP busca $e$ nas condições de trabalho por ela oferecidas.

Trabalhamos até hoje com alguns caras. Tem um cara que trabalha com a gente ainda, vai fazer o monstro [aqui ele se referia a uma produção que seria filmada]. Um deles virou crente, casou, foi pro interior. $\mathrm{O}$ outro sumiu. Parou também. (...) A gente conhece pouco ator que se encaixe pra gente. Por exemplo, tem um monte por aí. O Jam, o Kid... mas tem que encaixar no que a gente está pensando, né? (...) Não tem um ator que possa fazer uma cena gay que não esteja neste esteriótipo bombado, sabe. "Sou bombado, sou pedreirão". Então cai aí. (Rufus)

Acredito que, para além do que declarou Rufus, a ausência de homens também está ligada à tentativa de quebrar com ditames do pornô mais convencional, especialmente com o que se vê nos filmes lésbicos para homens. Por isso há um grande uso de sex toys (ou o joystick de vídeo game ou um cabo de pá) e um tratamento diferenciado das atrizes: elas podem opinar, escolher as cenas que farão e até mesmo com quem vão contracenar.

Em relação às atrizes há um padrão nas aparências e corpos utilizados nos vídeos e fotos: quase todas elas possuem modificações corporais - tatuagens e piercings - e não precisam necessariamente ser magras ou se enquadrarem em padrões de beleza mais convencionais. No site há inclusive uma parte (Xgirls) em que as 
Altporn, corpos, categorias e cliques

meninas podem se candidatar a participarem das produções ou terem suas fotos divulgadas. Os pré-requisitos para tal são, segundo termos nativos: ter maioridade legal, gostar de pornografia, enviar fotos com boa luz e resolução, não ter problemas com a nudez e não dar importância à opinião das outras pessoas. Além disso, a seleção do elenco é feita por eles mesmos, tendo já participado tanto mulheres já envolvidas com o mercado erótico principalmente prostituição - quanto outras sem qualquer ligação prévia. O padrão corporal privilegiado por eles ( $e$ oposto ao da pornografia mainstream) fica claro nessa fala de Lola:

$\mathrm{O}$ que a gente tem nesse pornô convencional, mainstream, mais conhecido? A gente tem mulheres com unhas compridas, cabelo comprido, bunda gigante, sem tatuagens, peitudas e magrelas. A gostosa. É isso que a gente tem. A XXP tem isso também? Tem. Mas ela tem a menina ali da esquina. Sabe, a vizinha. Que seria uma menina gordinha, seria uma menina com a unha desarrumada, a unha sem fazer, seria uma menina de cabelo curto, seria uma menina toda tatuada, seria uma menina que anda de skate, seria uma menina que tem banda de rock. Podia ser eu. Podia ser qualquer pessoa. Tem um filme que a gente faz com uma senhora e não é uma senhora MILF. Quando você vai fazer com uma mulher mais velha, você faz com MILF, né? A mãe que você poderia comer. E daí você faz a gostosa. No nosso caso não. É uma mulher - desculpa - mais zoada. Ela está ali dentro de um padrão comum. Ela é dona de casa. Com cara de dona de casa.

Os cenários presentes nos vídeos e fotos também tentam fugir do convencional. Com menos produção e menos montagem, a ideia é gravar em lugares inusitados, que às vezes flertam com aquilo considerado sujo e mais decadente (de novo volta aqui a marca do submundo). Aparecem nos vídeos, quartos de motéis baratos, masmorras de clubes BDSM, uma fábrica de temperos desativada, ruas pouco movimentadas, um centro "(anti)cultural" 
localizado próximo à Rua Augusta e bastante conhecido na cena alternativa de São Paulo e a própria sala ${ }^{21}$ da produtora.

Em relação às praticas sexuais $e$ às cenas em si, grande parte dos vídeos da XXP apresentam apenas meninas, envolvidas em sexo lésbico ou se masturbando (e para tal elas utilizam diversos tipos de acessórios e sex toys). Há também grande ênfase em produções que contemplem diferentes fetiches $e$ as práticas BDSM. Veio daí a criação da Fetxxx ${ }^{22}$. A ideia é mostrar práticas sexuais, tais como, fendom, pet play, leather, spanking, podolatria, pissing. Como as práticas BDSM e fetichistas (ou kink como são conhecidas no mercado pornô internacional) tensionam os limites da sexualidade e do sexo mais convencional, elas entram como parte do segmento altporn como um todo. De todo modo, assim como os corpos mostrados são bastante plásticos, as práticas sexuais também o são. A única restrição aparente envolve escatologia, sexo com animais ou outros atos enquadrados dentro do gênero conhecido como pornografia bizarra.

Por fim, vale uma nota acerca do mercado consumidor. Algo que me intrigava desde o início era saber se eles conseguiam ter uma ideia de quem era o público de pornografia alternativa no Brasil. Ao inquirir Lola e Rufus sobre o assunto recebi respostas muito parecidas: a de que havia um certo núcleo de pessoas interessadas nesse tipo de vídeos e que a maioria delas tinha uma relação muito próxima com a internet $e$ as plataformas digitais. Nos dizeres de Lola, a XXP é "pornografia de nerds". Acredito que isso corrobora o que disse ao longo deste texto: quem consome altporn também está consumindo um estilo de vida específico $e$

\footnotetext{
${ }^{21}$ A sala é bem pequena e de fora aparenta ser apenas mais um escritório. Nos dias de filmagens, ela passa por uma arrumação e eles criam algum cenário para os filmes, mas tudo bastante simples e feito por eles mesmos. Em uma das gravações que assisti, o fundo era um papel de parede com vários cavalos com um dildo na cabeça (de longe pareciam unicórnios).

22 Todo o conteúdo deste site também pode ser encontrado na XXP, mas ele serve como um direcionador de tráfego e como um agregador de informações mais segmentadas para os apreciadores de pornografia fetichista.
} 
Altporn, corpos, categorias e cliques

ligado a certas tendências que seriam consideradas alternativas, independentes ou mesmo modernas.

O que tentei mostrar neste artigo, fruto de uma pesquisa em andamento, foram algumas de minhas perambulações on e offline na busca de entender de que modo a internet atua no mercado pornográfico brasileiro, segmentando-o e permitindo experiências como a XXP. Talvez um dos maiores achados até o momento foi mostrar que a junção entre pornografia $e$ internet gera relações que podem ir para além do erótico e do online. O que se tem são pessoas, categorias, convenções, tecnologia, sexo, pornografia, avatares, espaços, lugares e corpos em constante movimentação e circulação.

\section{Referências bibliográficas}

Agustín, Laura Maria. Introduction to the cultural study of commercial sex. Sexualities, vol. 10, no 4, 2007, pp. 403-407. Disponível em: $<$ http://sexualities.sagepub.com/cgi/content/refs/10/4/403 > .

ATWOOD, Feona. No money shot? Commerce, Pornography and New Sex Taste Cultures. Sexualities, vol. 10, no 4, 2007, pp.441-456. Disponível em: $<$ http://sexualities.sagepub.com/cgi/content/abstract/10/4/441 > .

. Reading porn: the paradigm shift in pornography research. Sexualities, vol. 5, n 1, 2002, pp.91 -105.

BONIK, Manuel e SCHAALE, Andreas. The Naked Truth: Internet Eroticism and The Search. In: JACOBS, K.; JANSSEN, M. \& PASQUINELLI, M. (eds.) C'lickme. A netporn studies reader. Amsterdam, Institute of Network Cultures, 2007, pp.77-88.

BrAZ, Camilo. À MEIA-LUZ... Uma etnografia imprópria em clubes de sexo masculinos. Tese de Doutorado em Ciências Sociais, IFCH/Unicamp, 2010.

DíAz-BENITEZ, María Elvira. Nas redes do sexo. Os bastidores do pornô brasileiro. Rio de Janeiro, Zahar, 2010. 
FACCHINI, Regina. Entre umas e outras: mulheres, (homo)sexualidades e diferenças na cidade de São Paulo. Tese de Doutorado em Ciências Sociais, IFCH/Unicamp, 2008.

GREGORI, Maria Filomena. Prazeres Perigosos. Erotismo, gênero e limites da sexualidade. Tese de livre-docência. IFCH/Unicamp, 2010. (no prelo)

JACOBS, K., JANSSEN, M. \& PASQUINELlI, M. Introduction. In: C'lickme. A netporn studies reader. Amsterdam, Institute of Network Cultures, 2007.

KENDRICK, Walter. El Museo Secreto: La pornografía en la cultura moderna. Bogotá, Tercer Mundo Editores, 1995.

LEITE JR., Jorge. Das maravilhas e prodígios sexuais. A pornografia "bizarra" como entretenimento. São Paulo, Annablume, 2006.

MCCLINTOCK, Anne. Maid to order: commercial S/M and gender power. In: GIBSON, P. e GIBSON, R. (eds.) Dirty looks: women, pornography, Power. London, BFI, 1993, pp.207-231.

MiLLER, D. \& SLATER, D. Etnografia on e off-line: cybercafés em Trinidad. Horizontes Antropológicos, Porto Alegre, ano 10, $\mathrm{n}^{\circ}$ 21, jan/jun. 2004, pp.41-65.

PAASONEN, Susanna. Labors of love: netporn, Web 2.0 and the meanings of amateurism. New Media \& Society, London, Sage Publications, vol. 12, n 8, 2010, pp.1297-1312.

PARREIRAS, Carolina. Sexualidades no pontocom: espaços e (homo) sexualidades a partir de uma comunidade online. Dissertação de Mestrado, IFCH, Universidade Estadual de Campinas, 2008.

PRECIADO, Beatriz. Manifesto contra-sexual. Madrid: Pensamiento/Opera Prima, 2007.

SLATER, Don. Trading sexpics on IRC: embodiment and authenticity on the internet. Body \& Society, London, Sage Publications, 4 (4), 1998, pp.91-117.

STARK, Philip. 2008. The effectiveness of Internet content filters. I/S, A Journal of Law and Policy for the Information Society, 4, pp.411-429.

TANCER, Bill. Click. What millions of people are doing online and why it matters. New York, Hyperion, 2009. 
Altporn, corpos, categorias e cliques

WiLliamS, Linda. Screening Sex. Durham/London, Duke University Press, 2008.

. Hard Core. Power, pleasure, and the "Frenzy of the visible". Berkeley/Los Angeles/London, University of California Press, 1999. 